\title{
APROVEITAMENTO DA GLICERINA PROVENIENTE DA PRODUÇÃO DE BIODIESEL NA OBTENÇÃO DE HÍBRIDO DE CAULINITA PARA ADSORÇÃO DE $\mathrm{Cr}^{3+}$
}

\author{
Edimilson Cândido Leonel, Emerson Henrique de Faria, Rosalinda Chedian Pimentel, Eduardo José Nassar*, Katia Jorge \\ Ciuffi, Márcio José dos Reis e Paulo Sergio Calefi \\ Universidade de Franca, Av. Dr. Armando Salles Oliveira, Parque Universitário, 201, 14404-600 Franca - SP, Brasil
}

Recebido em 12/11/11; aceito em 1/3/12; publicado na web em 15/6/12

\begin{abstract}
UTILIZATION OF GLYCERIN FROM BIODIESEL PRODUCTION TO OBTAINING KAOLINITE HYBRID FOR Cr ${ }^{3+}$ ADSORPTION. The aim of this work was to contribute to the creation of new ways of treating wastewater contaminated with $\mathrm{Cr}^{3+}$, based on solid-liquid adsorption. An adsorbent material was prepared by functionalization of kaolinite with glycerin biodiesel byproduct. This material was tested for adsorption performed using a batch method, and results showed that inclusion of glycerin in the structure of kaolinite led to a significant increase in the capacity of $\mathrm{Cr}^{3+}$ adsorption. This contributes to the allocation of by-product of biodiesel and to the treatment of effluents from tanneries.
\end{abstract}

Keywords: adsorption; chromium; kaolinite.

\section{INTRODUÇÃO}

\section{Biodiesel e glicerina}

O biodiesel é comumente conhecido como um combustível renovável e sustentável, no entanto a utilização destes dois conceitos deve, em certos casos, ser vista com reserva. Como renovável entende-se que as matérias-primas e insumos sejam oriundos de fontes naturais, como plantas e animais, e por esta razão, podem ser utilizados e posteriormente repostos, enquanto o pressuposto de sustentabilidade ocorre quando determinado processo de produção ou produto tem a capacidade de suportar o consumo de maneira adequada. ${ }^{1}$ Há ainda uma série de problemas a serem resolvidos, relacionados ao biodiesel, para tornar este combustível sustentável nas dimensões social, econômica e ambiental. Dentre estas medidas, talvez a mais importante seja a criação de possibilidades de utilização dos subprodutos gerados. ${ }^{1}$

A reação de transesterificação alcoólica de óleos e gorduras produz ésteres de ácidos graxos (biodiesel) e a glicerina como principal subproduto. Para cada $900 \mathrm{~mL}$ de biodiesel produzido há uma consequente produção de $100 \mathrm{~mL}$ de glicerina. ${ }^{2}$ Nesta proporção, são produzidos aproximadamente $230 \mathrm{mil} \mathrm{m}^{3}$ de glicerina a cada ano para cumprir a exigência imposta pelo B5 (meta estipulada pelo governo que impõe a adição de $5 \%$ de biodiesel a todo diesel comercializado em território nacional).

Mesmo a glicerina sendo um material industrialmente versátil, com possibilidades de transformação em diversos produtos, a enorme quantidade deste insumo produzido pela transesterificação excede em muito a capacidade de absorção do mercado nacional. Um aspecto fundamental nesta avaliação é que a glicerina bruta possui impurezas que impedem seu uso em muitas das aplicações convencionais, em substituição à glicerina comercial.

Atualmente pouco mais de $30 \mathrm{mil} \mathrm{m}^{3}$ de glicerina comercial são consumidos anualmente no Brasil, um volume menor que a quantidade de glicerina produzida. ${ }^{3}$ Além disso, há uma limitação na capacidade de tratamento de glicerina bruta no país, que conta apenas com 4 unidades de refino capazes de absorver os grandes volumes gerados de glicerina bruta. ${ }^{4}$ Assim, é necessário encontrar novas saídas para a utilização deste subproduto de maneira direta. ${ }^{5-7}$

*e-mail: ejnassar@unifran.br
O presente trabalho apresenta uma contribuição com o objetivo de encontrar alternativas viáveis para os excessos de glicerina bruta e propõe sua utilização na síntese de um material híbrido, mediante a funcionalização de caulinita com moléculas de glicerina.

\section{Materiais híbridos de caulinita}

A inserção de substâncias orgânicas no interior da estrutura da caulinita tem sido comumente reportada na literatura. ${ }^{8-11}$ A caulinita é um argilomineral com estrutura cristalina formada pelo empilhamento de lamelas. Cada lamela é constituída de duas folhas cristalinas: uma folha tetraédrica formada por sílica e outra octaédrica formada por alumina, ambas mantendo-se coesas pelo compartilhamento de átomos de oxigênio. ${ }^{8-11}$ Moléculas orgânicas podem reagir covalentemente com o grupo aluminol (Al-OH) superficial e dos espaços interlamelares da caulinita, eliminando água, o que caracteriza a funcionalização..$^{8-11}$

A síntese de um material híbrido de caulinita com determinada substância orgânica se dá mediante a formação prévia de um material precursor. Nesta etapa, uma molécula altamente polar e de tamanho pequeno, geralmente dimetilsulfóxido, é inserida no interior da caulinita, a fim de que aumente seu espaçamento interlamelar, o que possibilita a inserção das moléculas ligantes e a formação da ligação entre a molécula orgânica e a matriz inorgânica. ${ }^{12-15}$ Por conseguinte, a síntese do híbrido é possível pela substituição do dimetilsulfóxido, no interior da lamela, pela molécula de interesse. Dependendo das condições termodinâmicas nas quais esse processo ocorre, pode haver a formação de materiais híbridos com moléculas orgânicas funcionalizadas (ligação covalente) ou simplesmente intercaladas (moléculas ligadas por ligações fracas, como ligações de hidrogênio e forças de van der Waals). A funcionalização de caulinita com alcoóis, dióis e polióis, incluindo a glicerina, já foi reportada em alguns trabalhos. ${ }^{8,12,16}$

Novas tecnologias envolvendo materiais híbridos representam um grande avanço e permitem melhorias e reformulações de uma infinidade de processos. Possibilitam também a substituição de materiais e métodos nocivos ao meio ambiente. $\mathrm{O}$ estudo das propriedades de materiais híbridos a partir de caulinita se justifica, devido ao baixo custo deste argilomineral e às aplicações industriais possíveis para os mesmos. 


\section{Adsorção de metais pesados de efluentes}

Uma importante aplicação de materiais híbridos, que tem sido muito estudada recentemente, é sua utilização como adsorventes para os mais diversos tipos de substâncias, sobretudo para íons de metais potencialmente tóxicos de efluentes industriais. ${ }^{17-22}$ Com esse propósito, vários materiais como a haloisita, ${ }^{20}$ saponita ${ }^{23}$ e vermiculita, ${ }^{24}$ além da caulinita, ${ }^{25}$ têm sido estudados. Estes materiais híbridos são geralmente sintetizados através da modificação com substâncias orgânicas de matrizes inorgânicas e apresentam características das partes orgânica e inorgânica, conferindo propriedades especiais que não são possíveis para ambos os materiais isoladamente. No caso especial da adsorção de crômio, processos como a biossorção, ${ }^{26-29}$ adsorção por sílica modificada ${ }^{22}$ e o uso de materiais alternativos ${ }^{27}$ têm sido relados na literatura. $\mathrm{O}$ estudo da adsorção de crômio para tratamento de efluentes se justifica, devido ao potencial toxicológico desta espécie. ${ }^{26-29}$

De acordo com a classificação de Pearson, ${ }^{30}$ íons metálicos como o $\mathrm{Cr}^{3+}$ (ácido duro) possuem grande afinidade com hidroxilas (base dura), sendo possível, deste modo, a formação de complexo envolvendo as duas espécies, o que sustenta a possibilidade de produção de adsorventes para este íon produzido a partir de glicerina, rica em hidroxilas.

\section{Contaminação de efluentes por crômio}

A comunidade científica é unânime em considerar que a emissão descontrolada de águas residuais com metais pesados provoca sérios problemas ambientais e de saúde pública. ${ }^{26-29}$ Atividades industriais como metalurgia, indústrias têxteis, curtumes, produção de plásticos, tintas, entre outros, têm como consequência a acumulação de metais nas águas, nos sedimentos dos rios e nos organismos. ${ }^{26-29}$

A remoção de íons de metais potencialmente tóxicos de efluentes é importante não apenas ambiental como também economicamente, haja vista a possibilidade de reutilização destes metais e, também, da água presente no efluente. No entanto, leis ambientais desatualizadas quanto à imposição de parâmetros ambientais resultaram, ao longo dos anos, na escolha por uma metodologia mais econômica para o tratamento destes efluentes, ainda que resulte em resíduos secundários. ${ }^{31}$

Em indústrias que utilizam íons metálicos em seus processos, o tratamento dos efluentes é normalmente feito pela elevação do $\mathrm{pH}$, que resulta na formação de hidróxidos pouco solúveis, ocorrendo a precipitação dos mesmos. Esta metodologia, apesar de simples e relativamente barata, possui algumas desvantagens significativas como a produção de resíduos secundários perigosos, a utilização de grandes quantidades de produtos químicos e a impossibilidade de recuperação dos metais. ${ }^{31,32}$

O curtume é um exemplo de indústria onde ocorre a utilização de metais no processo de produção. Os diferentes processos físico-químicos do curtume objetivam a limpeza da pele animal, a depilação, a adequação da estrutura celular da pele e, por fim, o curtimento, etapa principal do processo. A substância curtente mais comumente utilizada é o sulfato monobásico de crômio $\left(\mathrm{CrOHSO}_{4}\right)$ aplicada em forma de banhos nas peles animais. O resíduo do banho de curtimento é o principal e mais perigoso efluente desta indústria. ${ }^{32}$

Segundo o Serviço Nacional de Aprendizagem Industrial (SenaiRS), o tratamento de efluentes mais adequado para os curtumes deve incluir um tratamento preliminar para o banho residual de curtimento, devendo o crômio ser precipitado separadamente dos demais resíduos. No entanto, a metodologia que tem sido empregada se baseia numa etapa única, onde todos os metais são precipitados, formando um lodo residual que contém uma mistura de vários metais. $\mathrm{O}$ resíduo formado por esta prática é classificado como Classe 1 (maior nível de perigo ambiental). Devido aos riscos em potencial, este resíduo deve ser obrigatoriamente descartado em aterros sanitários adequados, o que acaba por se tornar uma fonte de gastos intermináveis para o curtume. Soma-se a isso a responsabilidade por muitos anos pelos rejeitos depositados no aterro. ${ }^{33}$

Face aos fatos mencionados, uma proposta de mudança na metodologia para o tratamento de efluentes de curtumes se justifica, devido à possibilidade de melhoria significativa. $\mathrm{O}$ processo de adsorção para o tratamento preliminar do banho residual do curtimento possibilita, entre outras coisas, a redução de custos devido à disposição de resíduos. O presente trabalho apresenta um estudo sobre a obtenção e utilização de um material adsorvente para íons $\mathrm{Cr}^{3+}$, produzido a partir de caulinita e glicerina residual de biodiesel, com a finalidade de aplicação no tratamento preliminar de efluentes de curtume.

\section{PARTE EXPERIMENTAL}

A purificação da caulinita foi feita por decantação de uma suspensão deste argilomineral em água destilada, baseando-se na Lei de Stokes. Após a obtenção de quantidade suficiente de caulinita purificada $(\mathrm{Ka})$, procederam-se às etapas para formação de caulinita intercalada com dimetilsulfóxido (Ka-DMSO). As etapas de purificação e intercalação da caulinita estão descritas na literatura. ${ }^{10}$

O material híbrido de caulinita funcionalizada com glicerina (KaGli) foi obtido conforme procedimentos descritos anteriormente por Detellier, ${ }^{12}$ para funcionalização de argilominerais com polialcoóis. Formou-se uma suspensão utilizando 3,5 g de Ka-DMSO e 175 mL de glicerina bruta (80,9\% glicerol, 12,2\% etanol, 4,5\% água e 2,4\% cinzas, em massa). A suspensão foi colocada em banho termostático a uma temperatura de $150{ }^{\circ} \mathrm{C}$. Após $48 \mathrm{~h}$, o material sólido foi recuperado por centrifugação e lavado com etanol e seco em estufa a $100{ }^{\circ} \mathrm{C} .{ }^{34,35}$

Os materiais sólidos foram caracterizados por difração de Raios X (DRX), material em pó, em um equipamento Rigaku MiniFlex II, empregando radiação filtrada $\mathrm{Cu} \mathrm{K}$, com velocidade de varredura de $2 \%$ min; espectroscopia vibracional na região do infravermelho com transformada de Fourier (IVTF) usando um espectrofotômetro Bomem MB100, utilizando pastilhas de KBr e análise térmica (TG/ DTG) em um TA Instruments - SDT Q600 - Simultaneous DTA-TGA, na faixa de temperatura de 25 a $1100{ }^{\circ} \mathrm{C}$ com razão de aquecimento de $20^{\circ} \mathrm{C} / \mathrm{min}$, em atmosfera de $\mathrm{N}_{2}$ e fluxo de $100 \mathrm{~mL} / \mathrm{min}$.

\section{Testes de adsorção}

O coeficiente de absortividade molar do crômio foi determinado utilizando um espectrofotômetro Hewlett-Packard, Diode array. Para isso, foram utilizadas 5 soluções de $\mathrm{CrCl}_{3}$ com concentrações de 2, 4, 6, 8 e $10 \mathrm{mmol} \mathrm{L}^{-1}$, a partir de solução estoque de $0,1 \mathrm{~mol} \mathrm{~L}^{-1}$. O coeficiente de absortividade molar do $\mathrm{Cr}^{3+}$ foi empregado para se determinar a concentração de $\mathrm{Cr}^{3+}$ em todas as soluções utilizadas, posteriormente, nos testes de adsorção.

Para os testes da cinética de adsorção foram preparadas 2 suspensões com $5 \mathrm{~mL}$ de solução de $\mathrm{CrCl}_{3}$ com concentração de 6 mmol L ${ }^{-1}$ e $0,1 \mathrm{~g}$ de cada material adsorvente (Ka-PUR e Ka-Gli). Colocaram-se as suspensões sob agitação magnética e, periodicamente, eram centrifugadas e tinham seu sobrenadante encaminhado para análise espectrofotométrica. Após análise, o sólido centrifugado era suspenso novamente no sobrenadante analisado, repetindo-se os procedimentos. Objetivou-se determinar, através da cinética de adsorção, o tempo gasto para que o processo de transferência de massa entre a solução de $\mathrm{Cr}^{3+}$ e a superfície do material adsorvente se estabilizasse. Após a determinação do tempo de operação, o mesmo foi usado como referência para os estudos de equilíbrio de adsorção. 
Em cada condição do processo, a quantidade de $\mathrm{Cr}^{3+}$ adsorvida (Q) foi calculada através da equação:

$$
Q=\frac{(C i-C f) V}{m}
$$

na qual $C i$ e $C f$ são, respectivamente, as concentrações de íons $\mathrm{Cr}^{3+}$ antes e após adsorção, $V$ é o volume da suspensão $m$ é a massa do material adsorvente utilizada no processo. A quantidade calculada representa a relação da quantidade de íons adsorvidos por unidade de massa de material adsorvente.

No estudo do equilíbrio de adsorção foram empregados dois conjuntos de tubos de ensaio contendo $5 \mathrm{~mL}$ de solução de $\mathrm{CrCl}_{3}$, com diferentes concentrações $\left(2,4,6,8\right.$ e $\left.10 \mathrm{mmol} \mathrm{L}^{-1}\right)$, e $0,1 \mathrm{~g} \mathrm{de}$ material adsorvente (Ka-PUR e Ka-Gli). O tempo utilizado nos testes de adsorção foi o tempo determinado pela cinética.

\section{RESULTADOS E DISCUSSÃO}

A Figura 1 apresenta os resultados obtidos pela espectroscopia de absorção na região do infravermelho para os materiais Ka-PUR, Ka-DMSO e Ka-Gli. No espectro da Ka-DMSO podem ser observadas duas bandas, em 3540 e $3503 \mathrm{~cm}^{-1}$, atribuídas às vibrações das hidroxilas interlamelares ligadas às moléculas de DMSO por ligações de hidrogênio. ${ }^{10-12} \mathrm{O}$ desaparecimento destas bandas no espectro obtido para a Ka-Gli sugere a substituição das moléculas de DMSO por moléculas de glicerina na região interlamelar da caulinita. Para a banda em $3620 \mathrm{~cm}^{-1}$, não se observam alterações nos espectros de todos os materiais, o que se explica, pois, essa banda é correspondente às hidroxilas intralamelares da caulinita que, devido à localização destas na estrutura da caulinita, estão impossibilitadas de sofrer alterações provocadas por mudanças no espaçamento basal do argilomineral. ${ }^{10-12}$ Outras bandas em 3695, 3668 e $3653 \mathrm{~cm}^{-1}$, também características de grupos hidroxilas, têm intensidades diminuídas e/ou foram deslocadas para outros números de onda. Estas mudanças estão relacionadas às hidroxilas interlamelares ligadas, por ligações de hidrogênio, a moléculas de DMSO e/ou glicerina. ${ }^{10-12} \mathrm{~A}$ modificação dos espectros na região das absorções características dos grupos $\mathrm{OH}$ interlamelares sugere a ocorrência de funcionalização de moléculas de glicerina neste espaço. A banda de absorção alargada em $3450 \mathrm{~cm}^{-1}$ representa a existência de água, que pode estar na estrutura do material ou na pastilha de $\mathrm{KBr}$ usada para realizar a análise espectrofotométrica. Esta banda também sofre a influência daquelas em 3540 e 3503 $\mathrm{cm}^{-1}$, características da interação de DMSO com a caulinita. Outra diferença entre o espectro dos materiais é a variação na intensidade da banda que aparece em $3600 \mathrm{~cm}^{-1}$. Esta banda, de acordo com Detellier et al. está relacionada à interação, por ligação de hidrogênio, envolvendo grupos $\mathrm{OH}$ da glicerina, que não foram ligados covalentemente, com aqueles grupos $\mathrm{OH}$ do aluminol da caulinita. ${ }^{36}$

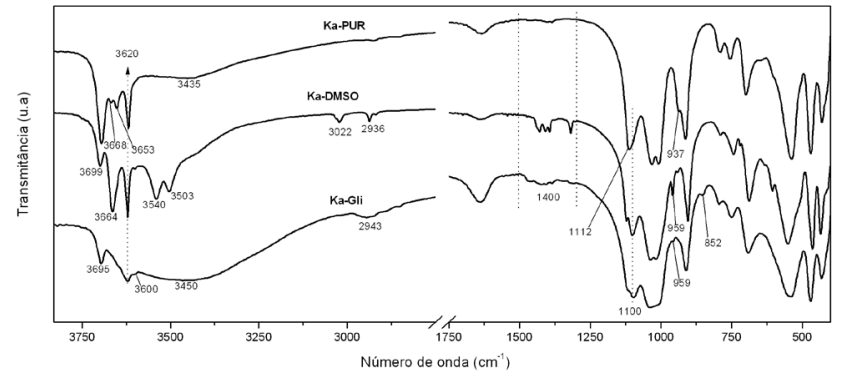

Figura 1. Espectros vibracionais obtidos por espectroscopia de absorção na região do infravermelho para Ka-PUR, Ka-DMSO e Ka-Gli
Ainda na Figura 1, pode ser observado no espectro de Ka-DMSO, em relação ao espectro da caulinita purificada, o deslocamento da banda em 937 para $959 \mathrm{~cm}^{-1}$, o que evidencia a intercalação de moléculas orgânicas no espaço interlamelar da caulinita. No espectro vibracional obtido para a Ka-Gli, a funcionalização pode ser evidenciada pelo desaparecimento da banda em $937 \mathrm{~cm}^{-1} \cdot{ }^{36}$ Bandas relativas à deformação da ligação C-H são observadas em $1400 \mathrm{~cm}^{-1}$, principalmente no espectro de Ka-DMSO, assim como são observadas as bandas atribuídas a grupos metilênicos na região entre 2800 e $3050 \mathrm{~cm}^{-1}{ }^{37}$ $\mathrm{O}$ aparecimento dessas bandas com menor intensidade também no material híbrido reforça a ideia de haver uma mistura de glicerina e DMSO remanescente no interior das lamelas da caulinita.

A Figura 2 mostra os difratogramas de raios $\mathrm{X}$ obtidos para Ka-PUR, Ka-DMSO e Ka-Gli. O difratograma para a Ka-PUR apresenta um pico em $2 \theta$ igual a $12,3^{\circ}$ que, de acordo com a Equação de Bragg $(\lambda=2 \mathrm{~d} \operatorname{sen} \theta)$ corresponde a um espaçamento basal de $7,19 \AA$ $\left(\mathrm{d}_{001}\right)$. Com a intercalação da caulinita com DMSO, ocorre uma expansão da distância entre as lamelas de caulinita e o pico de difração é deslocado para um valor de $2 \theta$ igual a $7,8^{\circ}$, que corresponde a um espaçamento basal de 11,33 $\AA$. O difratograma da caulinita funcionalizada, Ka-Gli, mostra um pico de difração em $2 \theta$ igual a 7,9 $9^{\circ}$, com intensidade diminuída em relação ao pico observado no difratograma para a Ka-DMSO. Isso indica que o material híbrido é lamelar, porém, um pouco menos organizado que o material precursor. O espaçamento basal calculado para a Ka-Gli corresponde a 11,19 A. A diminuição do espaçamento basal de Ka-Gli em relação ao espaçamento basal da Ka-DMSO é atribuída à formação de ligação covalente envolvendo os grupos $\mathrm{OH}$ presentes na glicerina e os grupos aluminol do argilomineral, ou seja, a condensação com a consequente liberação de água. Os resultados de DRX, aliados a outras técnicas analíticas, sustentam a tese de que a ligação covalente, característica da funcionalização, tenha ocorrido Os cálculos obtidos através do difratograma de cada material estão sumarizados na Tabela 1.

A Figura 3 apresenta as curvas obtidas por análises termogravimétricas da Ka-PUR e da Ka-Gli. A diferença de nível dos patamares

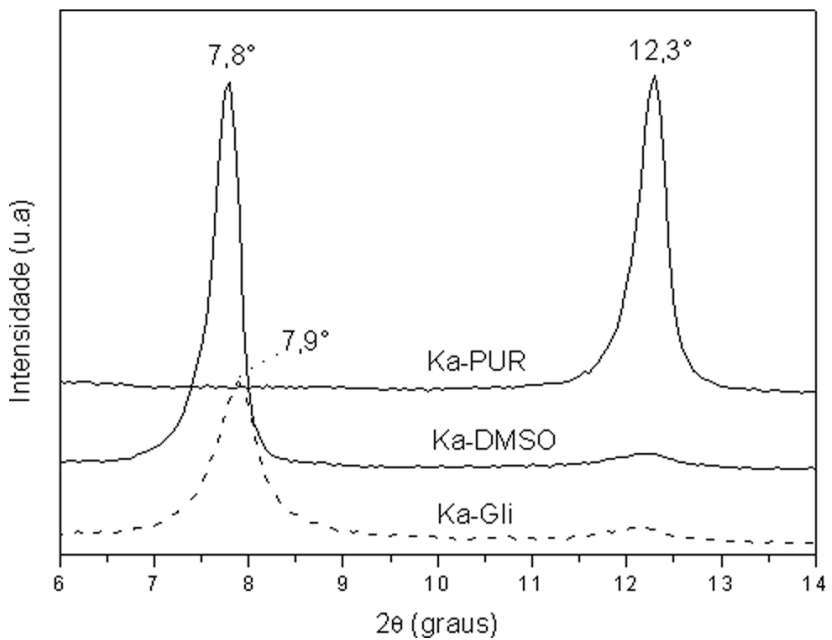

Figura 2. Difratogramas obtidos por difração de Raios X para Ka-PUR, Ka-DMSO, Ka-Gli)

Tabela 1. Dados obtidos por difratometria de Raios X

\begin{tabular}{cccc}
\hline Material & $2 \theta$ & $\mathrm{d}_{001}(\AA)$ & $\mathrm{d}_{001}(\mathrm{~nm})$ \\
\hline Ka-PUR & 12,30 & 7,190 & 0,719 \\
Ka-DMSO & 7,800 & 11,33 & 1,133 \\
Ka-Gli & 7,900 & 11,19 & 1,119 \\
\hline
\end{tabular}


que aparecem em temperaturas superiores a $600{ }^{\circ} \mathrm{C}$ se relaciona com a quantidade de material orgânico presente no híbrido. Esta quantidade de material orgânico corresponde principalmente à glicerina, sustentada pelo fato de que durante o processo de síntese do material $\mathrm{Ka}-\mathrm{Gli}$, as condições operacionais (tempo de reação e temperatura) são suficientes para a eliminação do DMSO. ${ }^{10-12}$

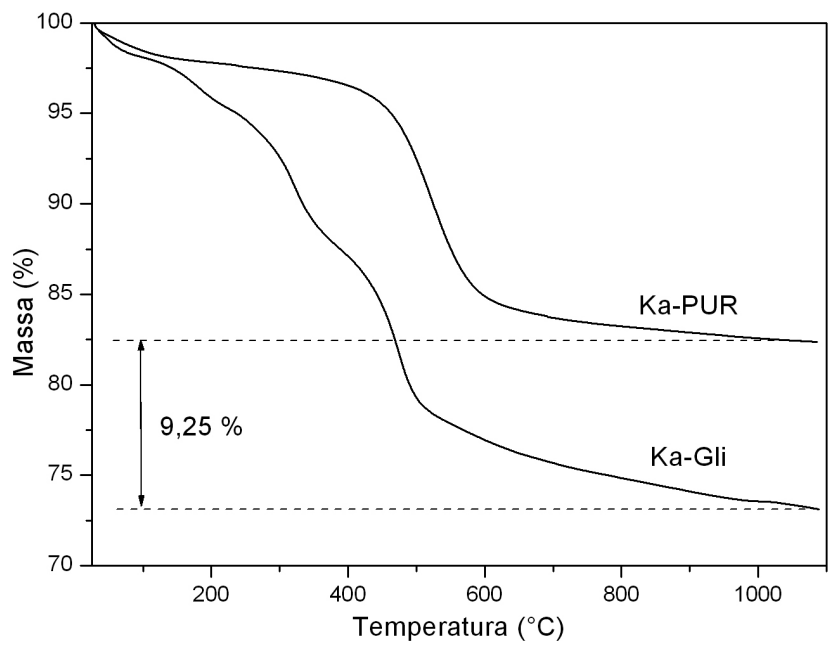

Figura 3. Curvas termogravimétricas obtidas para a Ka-PUR e Ka-Gli

A Figura 4 mostra as curvas TG e DTG da caulinita funcionalizada com glicerina. Nela é possível evidenciar os fenômenos de perda de massa e relacioná-los com suas respectivas temperaturas. A primeira etapa de perda de massa até aproximadamente $100^{\circ} \mathrm{C}$ é atribuída à eliminação de água. ${ }^{10-12} \mathrm{~A}$ segunda, entre 100 e $220^{\circ} \mathrm{C}$, com pico em $179^{\circ} \mathrm{C}$ é atribuída à eliminação de DMSO (temperatura de ebulição $=183{ }^{\circ} \mathrm{C}$ ) remanescente da síntese. ${ }^{10-12}$ A terceira etapa de decomposição, de 220 a $380^{\circ} \mathrm{C}$, com pico próximo a $318^{\circ} \mathrm{C}$ é atribuída à eliminação de moléculas de glicerina da estrutura do material híbrido. Esta atribuição fundamenta-se no ponto de ebulição da glicerina (290 ${ }^{\circ} \mathrm{C}$ ). A quarta etapa, que ocorre a partir de $380^{\circ} \mathrm{C}$, com pico em 470 ${ }^{\circ} \mathrm{C}$ é relativa à desidroxilação da caulinita, ou seja, ocorre a condensação das hidroxilas do aluminol, com a consequente formação de água. As quantidades aproximadas de massa eliminada nas etapas de decomposição foram, respectivamente, 2,2; 2,8; 7,6 e 14,6\%.

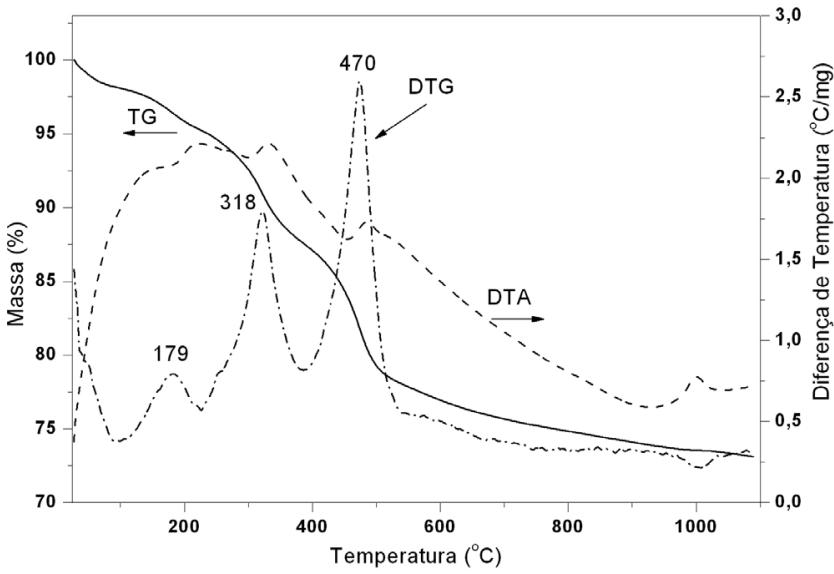

Figura 4. Curvas termogravimétrica $(T G)$ e termogravimétrica diferencial (DTG) do material híbrido Ka-Gli

Uma das mais importantes informações obtidas pela análise térmica do material híbrido refere-se à temperatura onde ocorre o pico relacionado à eliminação de glicerina, próximo a $318^{\circ} \mathrm{C}$. Este valor apresenta uma diferença significativa em relação à temperatura de ebulição da glicerina $\left(290^{\circ} \mathrm{C}\right)$. A curva DTA, da Figura 4, mostra que a eliminação da glicerina nesta etapa de decomposição é um processo exotérmico. Pode-se propor, com base neste resultado, que moléculas de glicerina estão ligadas às hidroxilas do aluminol por ligações covalentes, baseando-se no fato de a ligação covalente ser mais forte que a ligação de hidrogênio, necessitando, portanto, de maior energia para ser quebrada. Caso a molécula de glicerina se encontrasse apenas inserida no meio das lamelas, intercalada, a temperatura de desprendimento destas moléculas provavelmente seria próxima a $290{ }^{\circ} \mathrm{C}$, assim como ocorre para a eliminação do DMSO.

A Figura 5 apresenta os resultados obtidos pelo estudo de cinética de adsorção de $\mathrm{Cr}^{3+}$, ou seja, a variação da concentração de $\mathrm{Cr}^{3+}$ ao longo do tempo de processo. Observa-se que a quantidade de $\mathrm{Cr}^{3+}$ adsorvida ao material híbrido (Ka-Gli) se mantém praticamente constante após um período de $300 \mathrm{~min}$, o que evidencia que o processo de transferência de massa atingiu o estado de equilíbrio.

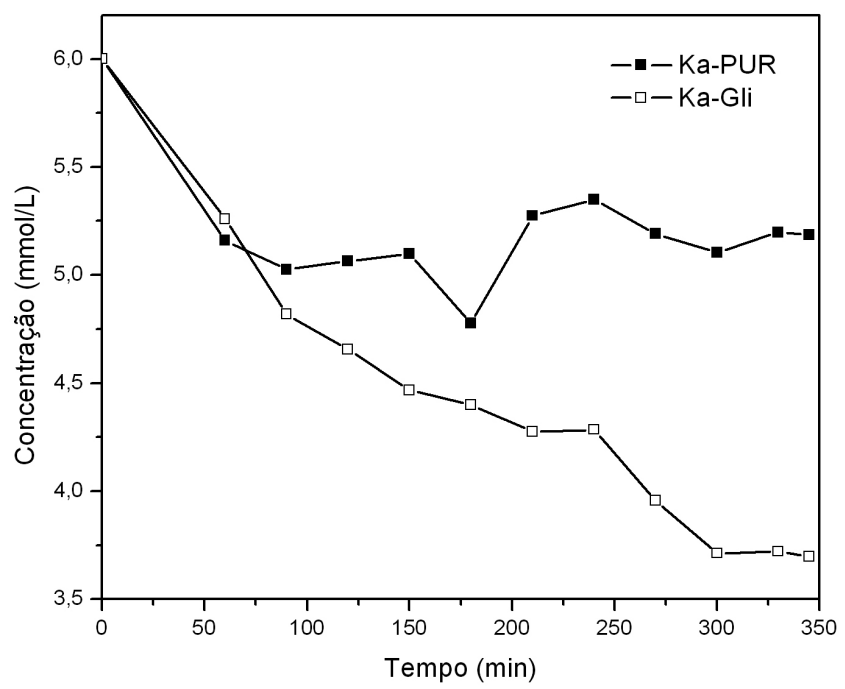

Figura 5. Variação da concentração de $\mathrm{Cr}^{3+}$ em função do tempo de contato para os dois materiais adsorventes, Ka-PUR e Ka-Gli

A Figura 6 apresenta as isotermas obtidas pelo estudo de equilíbrio de adsorção. Os resultados mostraram que o material híbrido Ka-Gli possui maior capacidade de adsorção que a Ka-PUR, o que se observa ao longo de toda a isoterma. A quantidade máxima de material adsorvido para a Ka-Gli foi da ordem de $0,051 \mathrm{mmol} \mathrm{g}^{-1}$, enquanto que para a Ka-PUR a quantidade máxima adsorvida foi da ordem de

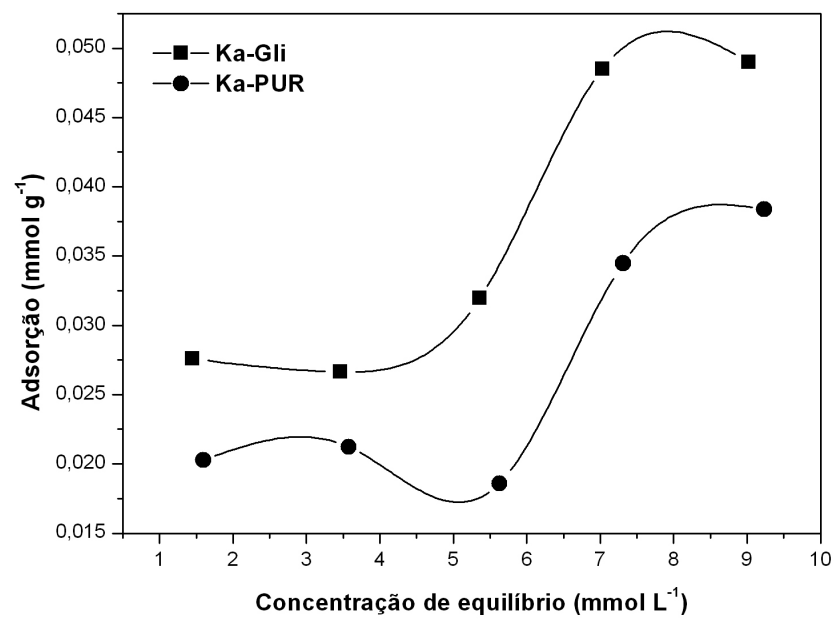

Figura 6. Isotermas de adsorção de íons $\mathrm{Cr}^{3+}$ em Ka-PUR e em Ka-Gli 
0,037 $\mathrm{mmol} \mathrm{g}^{-1}$, o que significa uma capacidade de adsorção cerca de $38 \%$ maior para o adsorvente Ka-Gli. A quantidade adsorvida determinada para a caulinita pura está de acordo com a apresentada na literatura por Dogan et al., que estudaram a adsorção de $\mathrm{Cr}^{3+}$, além de outros cátions, variando as condições experimentais (temperatura, $\mathrm{pH}$, tempo e concentração inicial de $\left.\mathrm{Cr}^{3+}\right) \cdot{ }^{37}$ Este resultado indica que a glicerina apresenta um papel importante para o aumento da capacidade de adsorção do $\mathrm{Cr}^{3+}$, o que pode ser explicado em função de a glicerina aumentar a quantidade de sítios $(\mathrm{OH})$ para a adsorção. ${ }^{30}$

\section{CONCLUSÕES}

A formação do material híbrido de caulinita com glicerina proveniente da produção do biodiesel foi obtida com sucesso, de acordo com as informações obtidas pelo conjunto de técnicas de caracterização utilizadas. O híbrido de caulinita com glicerina é capaz de adsorver íons $\mathrm{Cr}^{3+}$ de forma mais eficiente e em maior quantidade que a caulinita purificada, o que permite concluir que a glicerina, proveniente da produção do biodiesel, contribuiu efetivamente para um aumento significativo da capacidade de adsorção de $\mathrm{Cr}^{3+}$.

A possibilidade de desenvolvimento de um adsorvente para $\mathrm{Cr}^{3+}$, produzido a partir de caulinita e glicerina do biodiesel, representa uma proposta viável para o tratamento de efluentes de indústrias que contenham o $\mathrm{Cr}^{3+}$ como contaminante, como é o caso do curtume. A utilização do subproduto do biodiesel representa, portanto, uma importante contribuição na promoção da sustentabilidade do processo de produção deste biocombustível.

\section{REFERÊNCIAS}

1. Moret, A. S.; Sganderla, G. C. S.; Guerra, S. M. G.; Marta, J. M. C.; Espaço Energia 2009, 2, 14.

2. Rinaldi, R.; Garcia, C.; Marciniuk, L. L.; Rossi, A. V.; Quim. Nova 2007, 30, 1374.

3. Ferrari, R. A.; Oliveira, V. S.; Scabio, A.; Quim. Nova 2005, 28, 19.

4. Guimarães, J. L.; Satyanarayana, K. G.; Wypych, F.; Ramos, L. P.; Anais do I Congresso da Rede Brasileira de Tecnologia de Biodiesel, Brasília, Brasil, 2007.

5. Hesse, H.; Cremonese, E. B.; Schneider, R. C. S.; Nunes, M. R. S.; Bottega, D. P.; Resumos do XVI Encontro de Química da Região Sul, Blumenau, Brasil, 2008.

6. Medeiros, M. A.; Leite, C. M. M.; Lago, R. M.; Chem. Eng. J. 2012, 180, 364.

7. Medeiros, M. A.; Oliveira, D. L.; Sansiviero, M. T. C.; Araújo, M. H.; Lago, R. M.; J. Chem. Technol. Biotechnol 2010, 85, 447.

8. Gardolinski, J. E.; Tese de Doutorado, Faculdade de Matemática e Ciências Naturais de Christian-Albrechts, Alemanha, 2005.

9. Bergaya, F.; Theng, B. K. G.; Lagaly, G.; Handbook of Clay Science, Elsevier: Amsterdam, 2006.

10. de Faria, E. H.; Lima, O. J.; Ciuffi, K. J.; Nassar, E. J.; Vicente, M. A.; Trujillano, R.; Calefi, P. S.; J. Colloid Interface Sci. 2009, 335, 210.
11. de Faria, E. H.; Ciuffi, K. J.; Nassar, E. J.; Vicente, M. A.; Trujillano, R.; Calefi, P. S.; Appl. Clay Sci. 2010, 48, 516.

12. Detellier, C.; Kerstin, B. B.; Elbokl, T. A.; J. Mater. Chem. 2003, 13, 2566.

13. Frost, R. L.; Martens, W. N.; Kristof, J.; Horvath, E.; J. Phys. Chem. 2002, 106, 4162.

14. Frost, R. L.; Kristof, J.; Horvath, E.; Kloprogge, J. T.; J. Phys. Chem. 1999, 103, 9654.

15. Frost, R. L.; Kristof, J.; Paroz, G. N.; Kloprogge, J. T.; J. Phys. Chem. 1998, 102, 8519.

16. Marangon, A. A. S.; Dissertação de Mestrado, Universidade Federal do Paraná, Brasil, 2008.

17. Gupta, S. S.; Bhattacharyya, K. G.; Adv. Colloid Interface Sci. 2011, $162,39$.

18. Gupta, S. S.; Bhattacharyya, K. G.; Adv. Colloid Interface Sci. 2008, 140, 114.

19. Ghorbel-Abid, I.; Jrad, A.; Nahdi, K.; Trabelsi-Ayadi, M.; Desalination 2009, 246, 595.

20. Jiang, M.-q.; Wang, Q.-p.; Jin, X.-y.; Chen, Z.-1.; J. Hazard. Mater. 2009, 170,332 .

21. Aguiar, M. R. M. P.; Novaes, A. C.; Guarino, A. W. S.; Quim. Nova 2002, 25, 1145.

22. Airold, C.; Quim. Nova 2000, 23, 496.

23. Mellouk, S.; Cherifi, S.; Sassi, M.; Marouf-Khelifa, K.; Bengueddach, A.; Schott, J.; Khelifa, A.; Appl. Clay Sci. 2009, 44, 230.

24. Medeiros, M. A.; Sansiviero, M. T. C.; Araújo, M. H.; Lago, R. M.; Appl. Clay Sci. 2009, 45, 213.

25. Avila, L. R.; de Faria, E. H.; Ciuffi, K. J.; Nassar, E. J.; Calefi, P. S.; Vicente, M. A.; Trujillano, R.; J. Colloid Interface Sci. 2010, 341, 186.

26. Mishra, S.; Doble, M.; Ecotoxicol. Environ. Saf. 2007, 71, 874.

27. Hua, Y.; Baoyan, H.; Xianyan, L.; Hui, P.; Jinshao, Y.; Feng, Y.; Water Res. 2008, 42, 3981.

28. Sari, A.; Tuzen, M.; J. Hazard. Mater 2008, 160, 349.

29. Elangovan, R.; Philip, L.; Chandraraj, K.; Chem. Eng. J. 2008, 141, 99.

30. Pearson, R. G.; Science 1966, 151, 172.

31. Ferraz, A. I. O. F.; Tese de Doutorado, Universidade do Minho, Portugal, 2007.

32. Serviço Nacional de Aprendizagem Industrial do Rio Grande do Sul SENAI-RS; Introdução ao tratamento de efluentes industriais, Centro Tecnológico do Couro, 1991.

33. Dettmer, A.; Dissertação de Mestrado, Universidade Federal do Rio Grande do Sul, Brasil, 2008.

34. Menezes, R. R.; Ferreira, H. S.; Neves, G. A.; Ferreira, H. C.; Cerâmica 2003, 49, 120 .

35. Gardolinski, J. E.; Martins Filho, H. P.; Wypych, F.; Quim. Nova 2003, 26,30 .

36. Brandt, K. B.; Elbokl, T. A.; Detellier, C.; J. Mater. Chem. 2003, 13, 2566.

37. Dogan, M.; Turan, P.; Alkan, M.; J. Hazard. Mater. 2007, 148, 56. 